\title{
Published Title: TOURISM AND TEMPERATURE EFFECTS ON THE ELECTRICITY CONSUMPTION OF THE HOSPITALITY SECTOR
}

\section{Preprint Title: TESTING TOURISM AND TEMPERATURE EFFECTS ON ELECTRICITY CONSUMPTION IN THE HOSPITALITY SECTOR:A STUDY FOR THE SPANISH MEDITERRANEAN PROVINCES}

María del P. Pablo-Romero ${ }^{a}$, Rafael Pozo-Barajas ${ }^{\mathrm{b}}$, and Javier Sánchez-Rivas ${ }^{\mathrm{c}}$

\section{a. Corresponding author}

Department of Economic Analysis and Political Economy

Faculty of Economics and Business Sciences, University of Seville

Ramon y Cajal 1, 41018 Seville, Spain

Tel.: +34954 557 611. Fax: +34 954557629

mpablorom@us.es

b. Department of Financial Economy and Operations Management Faculty of Economics and Business Sciences, University of Seville Ramon y Cajal 1, 41018 Seville, Spain

Tel.: +34 954556 463. Fax: +34 954557570

pozo@us.es

c. Department of Economic Analysis and Political Economy

Faculty of Economics and Business Sciences, University of Seville

Ramon y Cajal 1, 41018 Seville, Spain

Tel.: +34 954557 611. Fax: +34 954554481

sanchezrivas@us.es

\begin{abstract}
The EU has recently presented a strategic long-term vision for a climate-neutral economy by 2050 , considering that climate change is a serious concern for Europeans. A great socio-economic transformation is necessary, affecting all economic sectors. On the one hand, the EU considers that is necessary to achieve net zero greenhouse gas emissions by 2050 , on the other hand, sectors need to adapt to a warming climate. Focusing on the tourism sector, and using panel data referring to 12 Spanish
\end{abstract}


Mediterranean provinces and the 1999-2014 time period, this study tests the tourist stays and temperature effects on the hospitality sector electricity consumption, by estimating extended Energy Environmental Kuznets curves (E-EKC) for the sector. The results show that the E-EKC hypothesis is not supported. Instead, electricity consumption progressively increases as tourism grows. In addition, the results indicate that temperature variables have notable influence over the electricity use, with a positive influence of global warming on electricity consumption. Finally, results also show positive relationships between overnight stays in hotels with higher star ratings and electricity use, while no significant price effects are observed. Electricity saving measures and renewable electricity generation promotion are recommended, especially in the highest energy consuming establishments.

Keywords: Tourism, hospitality sector electricity use, temperatures, Spanish Mediterranean provinces

JEL code: 013, 044, C23, Q01, Z23 
- Tourist stays and temperature effects on the hospitality electricity consumption are tested.

- The study refers to 12 Spanish Mediterranean provinces in 1999-2014

- An extended Energy Environmental Kuznets curves (E-EKC) is tested

- Electricity consumption progressively increases as tourism grows.

- Temperature variables have notable influence over the electricity use 


\title{
TESTING TOURISM AND TEMPERATURE EFFECTS ON ELECTRICITY CONSUMPTION IN THE HOSPITALITY SECTOR: A STUDY FOR THE SPANISH MEDITERRANEAN PROVINCES
}

\begin{abstract}
The EU has recently presented a strategic long-term vision for a climate-neutral economy by 2050 , considering that climate change is a serious concern for Europeans. A great socio-economic transformation is necessary, affecting all economic sectors. On the one hand, the EU considers that is necessary to achieve net zero greenhouse gas emissions by 2050 , on the other hand, sectors need to adapt to a warming climate. Focusing on the tourism sector, and using panel data referring to 12 Spanish Mediterranean provinces and the 1999-2014 time period, this study tests the tourist stays and temperature effects on the hospitality sector electricity consumption, by estimating extended Energy Environmental Kuznets curves (E-EKC) for the sector. The results show that the E-EKC hypothesis is not supported. Instead, electricity consumption progressively increases as tourism grows. In addition, the results indicate that temperature variables have notable influence over the electricity use, with a positive influence of global warming on electricity consumption. Finally, results also show positive relationships between overnight stays in hotels with higher star ratings and electricity use, while no significant price effects are observed. Electricity saving measures and renewable electricity generation promotion are recommended, especially in the highest energy consuming establishments.
\end{abstract}

Keywords: Tourism, hospitality sector electricity use, temperatures, Spanish Mediterranean provinces

JEL code: 013, 044, C23, Q01, Z23 


\section{Introduction}

In 2015, 195 parties assumed the Paris Agreement (United Nations, 2015) to reinforce the response to the threat of climate change (CC) by assuming targets for the post-2020 period. Likewise, in December 2018, in order to implement the Paris Agreement, parties reached agreement in Poland on a Rulebook. In addition to defining and publishing their Intended Nationally Determined Contributions (INDCs), parties have to determine the domestic policies to achieve those INDCs targets, focusing on accelerating the effort toward more ambitious greenhouse gas emissions (GGE) reduction targets in the coming years. These greater efforts are considered necessary as, according to the Intergovernmental Panel on Climate Change (IPCC) Special Report (IPCC, 2018), global warming has already exceeded pre-industrial levels by $1^{\circ} \mathrm{C}$ and continues to rise by around $0.2^{\circ} \mathrm{C}$ per decade. Therefore, if the international climate actions are not stepped-up, at some time after 2060, the global increase in temperature could reach $2^{\circ} \mathrm{C}$.

The European Union (EU) is aware of the conclusions of the IPCC Special Report. Therefore, in addition to the adoption of the target of at least a $40 \%$ reduction in GGE by 2030 to meet the Paris Agreement commitments (European Commission, 2015), the EU has recently presented a strategic long-term vision for a climate-neutral economy by 2050 (European Commission, 2018). In this document, it is stated that CC is a severe concern for Europeans, and that in order to fight against $\mathrm{CC}$, a greater economic and social transformation is necessary in Europe, affecting all economic sectors. This transformation must not only allow net zero GGE to be achieved by 2050 , but also sectoral transformation to adapt to a warming climate. 
In order to reduce emissions, the EU is already carrying out numerous sectoral energy measures as around $80 \%$ of GGE in the EU are generated by energy production and consumption (European Environment Agency, 2015). Many of these measures are related to energy efficiency, the use of renewable energies and the trend to electrify production systems (European Union, 2018). However, some forces may go against the control of energetic use, such as the economic growth of the sector or the increase in energy needs, due to the global warming process. It is therefore interesting to know how countries can reach the energy use reduction targets (at least fossil fuel energy use reduction) in each economic sector, and in an economic growth and global warming context. Therefore, sectoral studies testing the relationships between energy use, economic growth and temperatures may be of interest.

This paper is focused on the relationships between energy use, tourism growth and temperature effects. Focusing on the tourism sector is relevant, as this sector has a notable effect on growth, also causing notable energy use and a notorious impact on sustainability development. As stated in the UNWTO (2017) report, the tourism sector has a greater impact on society, the environment and the economy, as it represents $10 \%$ of world GDP, 7\% of total exports, and moves 1.2 billion tourists each year. Therefore, this sector is essential to achieving the objectives of the 2030 Agenda. In addition, testing the relationship between energy consumption and tourism growth may also be interesting to carry out because, as stated in Daniarta and Farasi (2015), tourist destinations consume disproportionately more energy than other geographical areas of similar size, which may be due to the fact that tourism services tend to use energyintensive technologies (Krstinić al., 2016). Therefore, studying the relationships between energy consumption and tourism is especially relevant. 
This study tests the tourist and temperature effects on the hospitality electricity consumption, by using panel data referring to 12 Spanish Mediterranean provinces and the 1999-2014 time period. The relationships between these variables are analyzed by testing an extended energy-EKC, where the effects of some tourism characteristics are also considered. Among them, the effect of the hospitality sector electricity price, the percentage of foreign tourist overnights to total, and of overnights in 4 and 5 star hotels to total.

Studying this relationship in the Spanish economy is pertinent as Spain recorded the highest tourism GVA in the EU (EUR 232,353 million in 2011), representing 58\% of the tourism GVA of the 16 EU countries for which data was available (Eurostat, 2017). Likewise, focusing on the Mediterranean provinces is of special interest as these 12 provinces are among the 15 with more tourist attractions, presenting similar characteristics.

The paper is structured in five sections. After the Introduction, in Section 2, the literature review is presented. In Section 3 data are presented, while in Section 4 the methodology used is explained. The results and the discussion are presented in Section 5, and finally Section 6 concludes.

\section{Literature Review}

The literature related to the energy consumption and economic characteristics in the tourism sector is scarce, being even scarcer when also related to global warming concerns. On the one hand, there are a small number of studies that analyze the tourism sector energy use linked to the process of economic growth. Among them may be highlighted the studies by Katircioglu (2014) and Katircioglu et al., (2014), analyzing the relationships between tourism, energy use and emissions in Turkey and Cyprus, respectively. Likewise, the study by Zaman et al., (2016), may also be cited, which 
investigates the relationship between economic growth, emissions, tourism development and other variables, testing the validity of the EKC in a variety of regions of the world, in the period from 2005 to 2013. In the same line, the study by Qureshi et al., (2017), evaluates dynamic linkages between sustainable tourism and energy in a panel of 37 tourism countries. On the other hand, the literature referring to the role of tourism related to $\mathrm{CC}$ and global warming is also scarce. In this regard, the studies by Scott et al., (2016a, 2016b), analyze the situation of tourism in the face of the CC and global warming process, showing both the vulnerabilities of the sector to the process and its necessary adaptation to it. Some studies have started studying the temperature effects on tourism, as for example in Grillakis et al., (2016), and Damm et al., (2017), which analyze the impacts of increasing $+2^{\circ} \mathrm{C}$ on summer and winter tourism demand in Europe, respectively.

Following this latter, some other recent papers (Pablo-Romero et al., 2017a; 2017b) have included the role of temperature in the analysis of the tourism effect on energy consumption. Focusing on the hospitality sector, the author analyzes how tourism induces energy use by controlling the temperature variable. Although the results indicate that its impact is not significant, the authors consider it may be due to the climate variable included in the model.

This current work goes beyond the previous papers and tests the interaction between tourism growth and electricity consumption in the hospitality sector, including the effect of temperature variables related to heating and cooling needs in the study, by introducing Cooling degree days (CCD) and Heating degree days (HDD) which, as far as we know, have not been previously studied in tourism energy use. Nevertheless, there is a tendency to use these variables in energy use studies, since they allow the non-linear effect of temperatures on energy use to be taken into account, 
distinguishing the effect of low and high temperatures on energy consumption (Fan and Hyndman, 2011; Blázquez et al., 2013; Mohammadi and Ram, 2017 and Serrano et al., 2017, for example). Likewise, this study goes beyond those mentioned, as it also includes non-linearity in the CDD and the HDD variables. The inclusion of nonlinearity in these variables is necessary as the effect of temperature on electricity consumption has been observed to be non-linear. Thus, for example, Chang et al., (2016), have observed that an increase in temperature increases energy demand, but the increased amount depended on the initial temperature level, indicating, therefore, that it is not adequate to consider the CDD effects as linear.

The relationships between energy use (electricity consumption), hospitality economic growth and CDD-HDD are analyzed by testing an extended energy-EKC. The energyEKC is a concept used by several researchers to analyze the non-linear relationships between income growth and energy consumption (Dong and Hao, 2018). Recently, some studies have tested the energy-EKC on several sectors, as notable sectoral heterogeneity in the energy consumption elasticity had been previously highlighted (Burke and Csereklyei, 2016). Among these studies, it is relevant to point out those by Liu et al., (2016), Pablo-Romero and Sánchez-Braza (2017) and Yin et al., (2015), related to the residential sector, those by Lin and Du (2015), and Pablo-Romero et al. (2017c) for the transport sector and those related to the tourism sector by Pablo-Romero et al (2017a; 2017b).

This paper tests the energy-EKC in the Spanish Mediterranean provinces for the hospitality sector, being therefore in line with previous energy-EKC and those related to the hospitality sector. Nevertheless, this current work goes beyond previous papers, as it includes in the study not only the CDD and HDD variables to take into account the different effect of cooling and heating needs in the electricity use, but also analyzes the 
non-linearity of each one of these climate variables in the hospitality sector electricity consumption.

This study also includes other variables in the model to test for other effects. Among them, the income variable, the percentage value of overnights in hotels with 4 and 5 stars to total, the percentage value of inbound tourist to total and the electricity variable.

\section{Data}

The panel data used in this study refers to the 12 Spanish Mediterranean provinces and the 1999-2014 time period. The main databases and characteristics of the variables used are described below.

\subsection{Hospitality sector electricity consumption and the tourist overnight stay data}

The electricity consumption data of the hospitality sector comes from the annual electricity consumption database by provinces offered by the Ministry for Ecological Transition (2019). The electrical consumption data for the hos pitality sector includes the consumption of the accommodation and food services sectors (sectors 55 and 56 of the NACE statistical classification). In this study, the values of electricity consumption are expressed in MWh per thousand inhabitants, converted to logs. The provincial population data are obtained from the INE database (2019).

In this study, provincial total overnight stays were used as an indicator of provincial tourism. The data was obtained from the series of occupations offered by Turespaña (2019). Previous studies have used various indicators to measure tourism. Camuñez et al., (2018) indicate that some previous studies, such as Belloumi (2010) and Dritsakis (2004), have used international tourist income to measure tourism. Others, such as Massidda and Mattana (2013), have used the number of foreign tourists, 
while some others, such as Gómez-Calero et al., (2014), and Pablo-Romero et al., (2017a), the number of overnight stays. Often, the first indicator is considered to be more appropriate for measuring tourism activity, although in provincial or regional studies, its use depends on the data availability. In the case of the Spanish provinces, Turespaña (2019) offers information on the number of hotel overnight stays and number of travelers staying at hotels. In this study, overnight stays have been used, as according to Gómez-Calero et al., (2014), this indicator is a good proxy for the income obtained from tourism. The data used in this study are overnight stays per thousand inhabitants, which are subsequently transformed into logarithmic terms.

\subsection{Temperature variables data}

The use of temperatures as control variables in studies that estimate demand functions for energy consumption (and especially electricity), or that analyze their determinants, is common in previous literature. Some studies use average temperature, as for example Lee and Chiu (2011), while others use temperature

range, as in Gam and Ben Rejeb (2012). Nevertheless, recent studies have a tendency to use the HDD and CDD temperature variables, as for example in Fan and Hyndman (2011), Blázquez et al., (2013), Mohammadi and Ram (2017) and Serrano et al., (2017).

Following these last studies, in this paper, the HDD and CDD variables have been used. CDD indicates the number of days in a year that the average temperature (Ti) surpasses a value (Tb). It is considered that surpassing this value indicates that cooling is necessary. The CDD value for a day is calculated as $\mathrm{CDDi}=(1-\gamma)(\mathrm{Ti}-\mathrm{Tb})$. If the average temperature is higher than $\mathrm{Tb}, \gamma=0$, and the $\mathrm{CDD}$ value is equal to ( $\mathrm{Ti}$ $\mathrm{Tb}$ ). If the average temperature is below $\mathrm{Tb}$, then $\gamma=1$ and $\mathrm{CDD}=0$. The sum of the CDDi for a year gives the annual CDD value. Additionally, HDD indicates the 
number of days (and time) that it is necessary to use heat. The HDD value for a day is calculated as $\mathrm{HDDi}=(1-\gamma)(\mathrm{Tb}-\mathrm{Ti})$. If the average temperature is lower than $\mathrm{Tb}$, then $\gamma=0$, and the HDD value is equal to (Tb-Ti). In any other case, $\gamma=1$ and HDDi $=0$.

The $\mathrm{Tb}$ temperature chosen has been $18^{\circ} \mathrm{C}$, and alternatively $15^{\circ} \mathrm{C}$ for heating and $22^{\circ} \mathrm{C}$ for cooling, as in Blazquez et al., (2013), for the residential sector in Spain. In addition, it is worth noting that many previous studies have used similar temperatures. In this sense, a review of the temperature variables and the base temperatures, used for analyzing the relationships between residential energy use and income, can be found in Fazzeli et al., (2016). All temperature data are calculated from the AEMET database (2019).

In addition, in order to evaluate the non-linearity of the climate variables, the squared values for the CDD and HDD have been considered. Boyd (2014) included these variables, considering that the heating or cooling needs are not to be lineal. Additionally, in this paper the CDD variable for temperature values between $18^{\circ} \mathrm{C}$ and $22^{\circ} \mathrm{C}(\mathrm{CDD} 18-22)$, and an HDD variable for temperature values between $15^{\circ} \mathrm{C}$ and $18^{\circ} \mathrm{C}$ (HDD15-18), is also considered when $\mathrm{Tb}$ is $22^{\circ} \mathrm{C}$ for $\mathrm{CDD}$ and $15^{\circ} \mathrm{C}$ for HDD. In this case, this range of temperatures have been previously considered as limits, so studies of what happens in these ranges are of special interest.

Figure 1 shows the Spanish Mediterranean provinces under study. The red color represents tourist overnight stays per inhabitant, being higher as the color becomes darker. The diameter of the pie chart included in each province represents the per capita electricity consumption in the hospitality sector, while each sector represents the proportion of hot and cool days of the year. Figure 1 shows a clear relationship between tourists and electricity consumption, in per capita terms. In addition, it may 
also be observed that when there are similar tourist per inhabitant rates, consumption increases with extreme hot and cold days (i.e., when the higher sectors are CDD22 and HDD15).

\section{[Insert Figure 1]}

\subsection{Control variables data}

Others variables have also been considered in this study to properly specify the estimated model.

Firstly, data on per capita provincial income are included to measure the possible effect of income on the electricity consumption in the hospitality sector. As an indicator of the level of provincial income, the per capita GDP level offered by the Spanish Regional Accounts (INE, 2019) has been used. In this study, data are measured in constant millions of Euros per thousand inhabitants, which are converted into logs.

Secondly, the effects of electricity prices on the electricity consumption have also been taken into account. Including price variables on E-EKC is not usual, but some papers have previously introduced it to approximate an energy demand function. In this line, it is worth noting the study by Pablo-Romero et al., (2017c), where an E-EKC is estimated for the transport sector. In order to calculate the electricity price related to the hospitality sector, the Blazquez et al., (2013), methodology has been used to calculate the price variable, as the electricity price is structured by sections according to the installed power, these sections being different through time. Therefore, the indicator used is a weighted average of the companies' revenues from electricity consumed, divided by the electricity consumption, and measured as constant thousands of Euros to kWh which have also been converted into logs. 
Finally, two other control variables were used in the study. The first one is the percentage value of overnights in hotels with 4 and 5 stars to total. In this sense, previous studies, as for example those by Tsai et al., (2014), Wang (2012) and Warnken et al., (2005), have highlighted that hotels which offer higher quality service use more energy. Therefore, it may be expected that higher starred hotels, which offer higher quality service cause energy consumption growth.

The second is the percentage value of inbound tourists to total. In this regard, several previous studies have highlighted that different tourists have different energy use patterns, related mainly to their travel and accommodation choice (Becken et al., 2003). In this case, it could be expected that inbound and national tourists could have different tourism choices, and therefore, it could also affect their energy consumption. Both variables are measured in percentage terms and calculated from the INE base data (INE, 2019)

\section{Methodology}

The general function for testing tourism and temperature effects on the hospitality sector electricity consumption can be as follows:

$E_{i t}=A_{i t}+\beta_{1} Y_{i t}+\beta_{2} T_{i t}+\beta_{3} T^{2} i t+\beta_{4} C D D_{i t}+\beta_{5} H D D_{i t}+\beta_{6} E x t T_{i t}+\beta_{7} S T_{i t}+\beta_{8} P_{i t}+e_{i t}$

where $E$ is the hospitality sector electricity consumption per inhabitants in logs, $Y$ is the GDP per inhabitants in logs, $T$ is the overnight stays per inhabitants in logs, $C D D$ is the Cooling degree days in logs, $H D D$ is the Heating degree days in logs, ExtT is the percentage value of inbound tourist to total, $S T$ is the percentage value of overnights in hotels with 4 and 5 stars to total, $P$ indicates electricity prices in logs, $A$ indicates the sum of the time and province effects, $i$ represents the Spanish Mediterranean provinces and $t$ the years from 1999 to 2014 . Finally, $e$ is the random error term. 
In addition to this specification, in order to evaluate the possible global warming effects reinforcing other variables, cross-products between ExtT and ST variables and CDD18 have also been tested in the model. These cross-product variables would measure the effects of the temperature on the effects of higher star hotels and foreign tourism on the hospitality sector electricity use. In this case, the specification is as follows:

$E_{i t}=A_{i t}+\beta_{1} Y_{i t}+\beta_{2} T_{i t}+\beta_{3} T^{2} i t+\beta_{4} C D D_{i t}+\beta_{5} H D D_{i t}+\beta_{6} E x t T_{i t}+\beta_{7} S T_{i t}++\beta_{8} P_{i t}$ $\beta_{0} C D D * S T_{i t}+\beta_{10} C D D * E x t T_{i t}+e_{i t}$

Likewise, in order to evaluate the non-linearity effect of global warming, squared values of $\mathrm{CDD}$ and HDD are considered. In addition, the estimation procedure was also completed by considering the squared values of CDD22 and HDD15 and CDD18-22 and HDD15-18. Therefore, the third equation proposed is as follows:

$E_{i t}=A_{i t}+\beta_{1} Y_{i t}+\beta_{2} T_{i t}+\beta_{3} T^{2} i t+\beta_{4} C D D_{i t}+\beta_{5} H D D_{i t}+\beta_{6} E x t T_{i t}+\beta_{7} S T_{i t}++\beta_{8} P_{i t}$ $\beta_{9} C D D^{2} i t+\beta_{10} H D D^{2}{ }_{i t}+\beta_{11}(\mathrm{CDD} 18-22)_{i t}+\beta_{12}(\mathrm{HDD} 15-18)_{i t}+e_{i t}$

In order to properly estimate equations [1] to [3], multicollinearity and the stochastic nature of the variables were examined. The variance inflation factors (VIF) were performed for each variable in order to test for multicollinearity. As expected, it is present, with some variables exceeding the value of 5. Therefore, all data were transformed into deviations from the geometric mean of the sample to rule out this problem, as previously performed in Pablo-Romero et al., (2017a).

Additionally, the Pesaran CD test (2004) for cross-sectional dependence, the Pesaran (2007) panel unit root tests (CIPS tests) and the Westerlund co-integration test (2007) were performed to study the stochastic nature of the series. As variables are I(1) (according to the CIPS test results), and the null hypothesis of no cointegration cannot be rejected for all the considered statistics (according to the Westerlund 
cointegration test results), the model was estimated in first-differences. In addition, estimating by using first differences allows the elimination of constant or fixed effects that may condition the electricity use in the Mediterranean provinces and which are not controlled by the model.

Using $\Delta$ to indicate first differences of the transformed variables, equations [1] to [3] may be rewritten as follows,

$\Delta E_{i t}=\Delta A_{i t}+\beta_{1} \Delta Y_{i t}+\beta_{2} \Delta T_{i t}+\beta_{3} \Delta T^{2}{ }_{i t}+\beta_{4} \Delta C D D_{i t}+\beta_{5} \Delta H D D_{i t}+\beta_{6} \Delta E x t T_{i t}+\beta_{7} \Delta S T_{i t}+$

$\beta_{8} \Delta P_{i t}+e_{i t}$

$\Delta E_{i t}=\Delta A_{i t}+\beta_{1} \Delta Y_{i t}+\beta_{2} \Delta T_{i t}+\beta_{3} \Delta T_{i t}^{2}+\beta_{4} \Delta C D D_{i t}+\beta_{5} \Delta H D D_{i t}+\beta_{6} \Delta E x t T_{i t}+\beta_{7} \Delta S T_{i t}+$

$\beta_{8} \triangle P_{i t}+\beta_{9} \triangle C D D^{*} S T_{i t}+\beta_{10} \triangle C D D^{*} E x t T_{i t}+e_{i t}$

$\Delta E_{i t}=\Delta A_{i t}+\beta_{1} \Delta Y_{i t}+\beta_{2} \Delta T_{i t}+\beta_{3} \Delta T_{i t}^{2}+\beta_{4} \Delta C D D_{i t}+\beta_{5} \Delta H D D_{i t}+\beta_{6} \Delta E x t T_{i t}+\beta_{7} \Delta S T_{i t}+$ $\beta_{8} \Delta P_{i t}+\beta_{0} \Delta C D D^{2} i t+\beta_{10} \Delta H D D^{2}{ }_{i t}+\beta_{11} \Delta(\mathrm{CDD} 18-22)_{i t}+\beta_{12} \Delta(\operatorname{HDD} 15-18)_{i t}+e_{i t} \quad$ [6]

where $\Delta \bar{A}_{i t}=\delta_{t}$.

Finally, in order to properly estimate previous equations, the estimated model has been chosen taking into account the Wooldridge test for autocorrelation (2002) and the Wald test for homoscedasticity (Greene, 2002) results. Accordingly, the feasible generalized least squares model (FGLS) was used to estimate equations [4] to [6].

\section{Results and Discussion}

Table 1 shows the estimate results of [4] when using, alternatively, CDD18, HDD18 and CDD22, HDD15 temperature variables. Additionally, the last two columns include the estimate results when eliminating the price variable, due to its lack of significance.

[Insert Table 1] 
The results indicate that the electricity E-EKC hypothesis for the hospitality sector is refused for the considered Spanish Mediterranean provinces, in the 1999-2014 period, as the $\mathrm{T}$ and $\mathrm{T}^{2}$ coefficients are positive and significant in all the performed estimates. Instead, the estimated coefficient signs show that there is an increasing relationship between both variables. Therefore, as tourist overnight stays in the Spanish Mediterranean provinces increase, so does the electricity consumption in the hospitality sector, with the increases rising as tourism grows. These results are in line with those observed in Pablo-Romero et al., (2017a), for the Spanish provinces.

Regarding the temperature variables, estimated coefficients for the CDD and the HDD variables are positive in all estimates. The results indicate that the estimated values for the CDD variables are all positive, indicating that an increase in temperature produces more need for cooling energy. These results are in line with previous studies referring to Greece and Portugal. In the first case, Asimakopoulos et al., (2012), estimate that an increase of $248 \%$ in cooling demand is expected due to $\mathrm{CC}$, while in the second case, Pinto et al., (2016), estimate a potential primary energy for cooling increase of $25 \%$.

In addition, the results also indicate that the estimated values for the HDD variables are positive, indicating that a decrease in temperature produces more energy need for heating, and therefore more electricity use in the sector. Nevertheless, it is worth noting, that when HDD is calculated by using the base temperature of $15^{\circ} \mathrm{C}$, the variable becomes non-significant, which could be related to the fact that if the temperature is too low, tourists would not come to these destinations, and therefore less energy use is needed, some hotels or restaurants close, or alternatively, a fuel substitution between electricity and fuels occurs. In this sense, it could interesting, in future research, to analyze how changes in temperature may have effects on tourism arrivals, and indirectly on electricity use. 
The estimated results also show positive and significant values in all estimates for the ST and Ext coefficients, both of these variables therefore having positive effects on electricity consumption. It could therefore be appropriate to reinforce the mentioned policies in higher star hotels and in those spaces usually used by inbound tourists. In this line, several studies indicate the possibility of saving energy use in these hotels. Thus, for example, the study by Alamri (2013) indicates how it was possible to save up to $15 \%$ of the total energy consumption in five star hotels, every year, by introducing Wireless Energy Technology. Likewise, the study by Hotel Energy Solutions (2011) indicates that there is a potential for $25-30 \%$ energy savings in the highest annual energy consumption hotels in southern Europe.

Finally, regarding the price variable, it should be highlighted that in the performed estimates no significance is observed. Additionally, it is worth noting that, excluding the price variable from the estimates does not notably change the estimated valued for the rest of the variables, as for example occurs in Pablo-Romero et al., (2017c), when estimating an E-EKC referring to the transport sector. The lack of significance of the price variable may be in line with the results obtained by Labandeira et al., (2012), who find that companies and large consumers of electricity are hardly affected by the variations observed in prices. These results may indicate that energy policies focusing on price may not have effects on electricity consumption, at least in the current ranges.

Table 2 shows the estimate results of [5] when using, alternatively, CDD18, HDD18 and CDD22, HDD15 temperature variables. Additionally, Table 2 also shows the estimate values when eliminating the price variable, because, as before, it is not significant in any case.

[Insert Table 2] 
Once again, the results indicate that the E-EKC hypothesis for the hospitality sector does not hold, with an increasing relationship between the studied variables. Likewise, as before, estimated coefficients for the CDD and the HDD variables are positive in all estimates, with the HDD variable becoming non-significant when using the base temperature of $15^{\circ} \mathrm{C}$. The estimated results also show positive and significant values in all estimates for the ST and Ext coefficients. Finally, it is also worth noting the positive and significant values for the cross-product between ST and the CDD variable. The results may indicate that these hotels may be offering more services, inducing more electricity use, and, as temperature becomes higher, the electricity use in these hotels becomes higher than in others. This may also be related to the comfort conditions offered in these establishments. Therefore, focusing on these kinds of hotels could be convenient when applying energy policies related to energy efficiency and renewable energy use. In this sense, ecolabels could be appropriate.

Finally, Table 3 shows the estimated coefficient values when estimating [6]. The second and third columns show the estimates when the squared values of the HDD and CDD are included in the function, but not the variable referring to the ranges HDD15-22 and CDD18-22. The fourth column shows the estimated coefficient of [6], and finally the fifth column shows the estimated coefficient of [6] when the price variable is not included, once again due to the lack of significance in the previous estimate.

\section{[Insert Table 3]}

Table 3 again shows that the E-EKC hypothesis is not supported for the hospitality sector in the Spanish Mediterranean provinces and that an increasing relationship is observed. Therefore, taking into account the results shown in Tables 1 to 3 , related to the tourism variable, it may be appropriate to implement some measures to compensate for the effect of tourism in increasing electricity consumption. In this line, two main 
policies could be appropriate to implement in order to avoid environmental damage linked to electricity consumption increases in the sector. First, more energy efficiency measures are needed to apply to compensate for the electricity consumption increase due to tourism growth. Nevertheless, authors such as Becken and Dolnicar (2016) found that companies have the perceptions that these projects are not always well-matched with productivity, the financial cost being considered an important barrier. Secondly, renewable energies could be promoted in a double sense: On the one hand, the use of renewable technologies may be used in the hospitality buildings. In this line, Chan et al., (2017), pointed out that hotel experts prefer solar systems. Thus, according to Gallo et al., (2014), these systems could supply up to $50 \%$ of hotels energy use in Southern EU countries, such as Spain. On the other hand, the use of renewable energies could be promoted for electricity generation, so that emissions related to this consumption increase would not provoke emissions generation. In this regard, the change in the energy mix could be appropriate. However, it is worth noting that stronger growth in renewable energy could be expected, due to the fact that solar and wind power are becoming more competitive, but there are some barriers that are still limiting the incorporation of renewables into the power generation, such as surplus energy storage (European Union, 2018). Several studies, such as the report by Deloitte (2016), consider that self-generation and self-consumption may play a very important role, pointing out that it could be convenient to allow free access and to not impose penalties for this form of energy generation-consumption.

Regarding the temperature coefficients estimated values, it is worth noting that the Table 3 results indicate that the hypothesis of non-linearity effects of temperature variables on the electricity consumption is supported. The positive value of the squared variable indicates an increasing elasticity of electricity consumption in the sector when 
the CDD increases. This is also reinforced by the CDD18-22 estimate value, as this value is lower than that obtained for CDD22, also indicating that, when temperature increases, the electricity use elasticity will also increase for cooling spaces. Therefore, if global warming occurs, and the other variables remain constant, the electricity consumption in the hospitality sector will tend to increase, this increase being higher as the temperature increases. These results are in line with those observed by Chang et al., (2016), who pointed out that the temperature increase would have more effect on energy use for higher temperature levels.

In the case of HDD coefficients values, the estimated values for HDD15 and HDD15-18 are positive, indicating that electricity consumption increases when temperatures become lower, so that more heating is necessary to warm spaces. Nevertheless, it is worth noting that the coefficient value is lower for the HDD15 than for the HDD15-18 variable, indicating that increasing the HDD for temperature ranges between $15-22^{\circ} \mathrm{C}$ provokes higher electricity needs than when increasing the HDD for temperatures below $15^{\circ} \mathrm{C}$. Likewise, this effect is also reinforced by the negative value for squared-HDD15, which indicates that the electricity consumption elasticity, with respect to HDD15, is decreasing as temperature goes down, and heating is needed. It can be expected then, that an increase of the temperatures that provokes an increase of temperate days in which the use of the heating is needed (temperatures below $18^{\circ} \mathrm{C}$ ), is going to cause an increase in the use of electricity in the hospitality sector.

Finally, it should be highlighted that the estimates have been performed considering the average daily temperature, without taking into account the wide range between maximum and minimum temperatures, and without differentiating by months or seasonal characteristics. Therefore, when data permits, it would be interesting to 
undertake further research on these questions, which could improve the results, especially for HDDs.

\section{Conclusions and policy implications}

The EU has recently presented a strategic long-term vision for a climate-neutral economy by 2050. As the EU considers that CC is a serious concern for Europeans, a multi-sectoral socio-economic transformation is considered to be necessary. On the one hand, the EU considers it necessary to achieve a net zero GGE by 2050, on the other hand, the adaptation of the economic sectors to a warming climate is considered necessary. This study focuses on the tourism sector's adaptation to temperature changes, by analyzing their effects on the hospitality electricity consumption.

Specifically, and using panel data referring to 12 Spanish Mediterranean provinces and the 1999-2014 time period, this study tests the tourist stays and temperature effects on the hospitality electricity consumption by estimating an extended E-EKC for the sector. In addition, in order to take into account the non-linearity temperature effects on electricity consumption, HDD and CDD are calculated for different temperature ranges and the squared values of variables are considered.

The results show that the E-EKC hypothesis is not supported, since it is observed that there is a growing relationship between the electricity consumption in the hospitality sector and the overnight stays. In addition, the results show that increased overnight stays in hotels with higher star ratings, increased presence of foreign tourists and higher income levels, tends to increase the electricity consumption in the hospitality sector. Likewise, the results show that electricity prices have no significant effects on the sectoral electricity consumption. 
Regarding the temperature effects, the results show a notable influence of temperature variables on the electricity use, as increasing $\mathrm{CDD}$ and HDD provoke electricity consumption increases. The results indicate that these effects are not linear. In the case of $\mathrm{CDD}$, the results indicate that the elasticity of the electricity consumption, with respect to $\mathrm{CDD}$, is increasing. Therefore, global warming will induce not only an increasing electricity use, but also higher temperature increases will tend to increase these effects.

In the case of HDD, the results also indicate positive effects, nevertheless, the elasticity values of the electricity use, with respect to the HDD, tends to be non-significant when the base temperature is lower. In addition, it is observed that although the elasticity is positive, it becomes lower as the variable grows, indicating that the effect is going to be lower as the temperatures become lower, or alternatively, that the effect will be greater when temperatures become higher.

The results indicate that tourism growth and global warming (increasing CDD and reducing HDD15 and increasing HDD, between 15 to 18 average temperature range) have a positive influence on hospitality electricity use. Therefore, it could be appropriate to implement some measures in order to control the increase in electricity use, at least the use of electricity from non-renewable sources. In this line, it could be appropriate to implement energy saving measures, especially in those hotels with highest energy use, as for example those with a high number of stars. Additionally, it could also be recommended to install renewable energy and electricity generation systems in hotels, especially if it is accompanied by state laws that do not punish electricity self-consumption. Finally, it is also considered appropriate to encourage the change in the electricity mix towards a more renewable generation. 
Additionally, taking into account these non-linear results on temperature, it could be convenient to delve into these non-linearity effects in future research, for example by differentiating the estimates by season. In addition, it could also be interesting to analyze how changes in temperature may have effects on tourism arrivals, and indirectly on electricity use.

Finally, it is also worth noting the positive and significant values for the ST variable and also for the cross-product. In this regard, the results may indicate that these hotels may be offering more services inducing more electricity use. In addition, as the temperature becomes higher, the electricity use in these hotels will become higher than in others.

\section{References}

AEMET (2019). AEMET OpenData. Agencia Estatal de Meteorología: Madrid. Available at http://www.aemet.es/es/datos_abiertos (Accessed on January 29, 2019).

Alamri, M. (2013). Analysing the Energy Performance of a Five Star Hotel Using Wireless Energy Technology The thesis is submitted to University College Dublin 'UCD' in part fulfilment of the requirements for the degree.

Asimakopoulos, D.A., Santamouris, M., Farrou, I., Laskari, M., Saliari, M., Zanis, G., Giannakidis, G., Tigas, K., Kapsomenakis, J., Douvis, C., Zerefos, S.C., Antonakaki, T. \& Giannakopoulos, C. (2012). Modelling the energy demand projection of the building sector in Greece in the 21st century. Energy and Buildings, 49, 488-498.

Becken, S. \& Dolnicar, S. (2016). Uptake of resource efficiency measures among European small and medium-sized accommodation and food service providers. Journal of Hospitality and Tourism Management, 26, 45-49.

Becken, S., Simmons, D. G., \& Frampton, C. (2003). Energy use associated with different travel choices. Tourism Management, 24(3), 267-277.

Belloumi, M. (2010), The relationship between tourism receipts, real effective exchange rate and economic growth in Tunisia. International Journal of Tourism Research, 12, 550-560.

Blázquez, L., Boogen, N. \& Filippini, M. (2013). Residential electricity demand in Spain: New empirical evidence using aggregate data. Energy Economics, 36, 648-657.

Boyd, G. A. (2014). Estimating the changes in the distribution of energy efficiency in the US automobile assembly industry. Energy Economics, 42, 81-87.

Burke, P. J., \& Csereklyei, Z. (2016). Understanding the energy-

GDP elasticity: A sectoral approach. Energy Economics, 58, 199-210. 
Camuñez, J. A., Pablo-Romero, M. P., \& Sánchez-Rivas, J. (2018). Tourism capital: Index for the Spanish provinces through confirmatory factor analysis. Tourism Economics, 24(7), 889-900.

Chan, E.S., Okumus, F. \& Chan, W. (2017). The Applications of Environmental Technologies in Hotels. Journal of Hospitality Marketing \& Management, 26(1), 23-47.

Chang, Y., Kim, C. S., Miller, J. I., Park, J. Y., \& Park, S. (2016). A new approach to modeling the effects of temperature fluctuations on monthly electricity demand. Energy Economics, 60, 206-216.

Damm, A., Greuell, W., Landgren, O., \& Prettenthaler, F. (2017). Impacts of +2 C global warming on winter tourism demand in Europe. Climate Services, 7, 3146.

Daniarta, S., \& Farasi, Y. A. (2015). Ecotourism of Tropical Regions with Renewable Energy Perspective in Indonesia. KnE Energy \& Physics, 2(2), 158-164.

Deloitte (2016). A sustainable energy model for Spain in 2050 Policy. Available at https://www2.deloitte.com/content/dam/Deloitte/es/Documents/estrategia/Deloit te_ES_Estrategia_Modelo-Energetico-Informe-Ingles.pdf (Accessed on January 29, 2019).

Dong, X.Y., \& Hao, Y. (2018). Would income inequality affect electricity consumption? Evidence from China. Energy, 142, 215-227.

Dritsakis, N. (2004), Tourism as a long-run economic growth factor: an empirical investigation for Greece using causality analysis. Tourism Economics, 10(3), 305-316.

European Commission (2015). Union and its Member States: Intended Nationally Determined Contribution of the EU and its Member States. Submission by Latvia and the European Commission on Behalf of the European Available online:

http://www4.unfccc.int/ndcregistry/PublishedDocuments/Spain\%20First/LV-0306-EU\%20INDC.pdf (accessed on February 1, 2019).

European Commission (2018). Brussels, 28.11.2018 COM (2018) 773 Final communication from the Commission to the European Parliament, the European Council, the European Economic and Social Committee, the Committee of the Regions and the European Investment Bank: A Clean Planet for all European strategic long-term vision for a prosperous, modern, competitive and climate neutral economy.

European Environment Agency (2015). Final energy consumption by sector and Fuel. Copenhagen: European Environment Agency.

European Union (2018). European Political Strategy Centre study: "10 Trends reshaping Climate and Energy".

Eurostat (2017). Tourism Satellite Accounts in Europe 2016 edition. Luxembourg: Publications Office of the European Union.

Fan, S. \& Hyndman, R.J. (2011) The price elasticity of electricity demand in South Australia. Energy Policy, 39(6), 3709-3719

Fazeli, R., Ruth, M., \& Davidsdottir, B. (2016). Temperature response functions for residential energy demand - A review of models. Urban Climate, 15, 45-59. 
Gallo, A., Gonzalez-Aguilar, J. \& Prodanovic, M. \& Romero, M. (2014). Analysis of Demand and Energy Saving at Different Types of Hotels with Integration of Solar Systems and Geothermal Heat Pumps. 10.18086/eurosun.2014.03.25.

Gam, I. \& Ben Rejeb, J. (2012) Electricity demand in Tunisia. Energy Policy, 45, 714720.

Gómez-Calero, M., Molina, J. A., \&. Pablo-Romero, M. (2014). Research note: Exploring the effect of tourism on economic growth in the Spanish provinces and autonomous communities, 1999-2008. Tourism Economics, 20(5), 11171124.

Greene W (2002). Econometric analysis, 5th ed. Upper Saddle River, New Jersey. New Jersey; Prentice Hall.

Grillakis, M. G., Koutroulis, A. G., Seiradakis, K. D., \& Tsanis, I. K. (2016). Implications of $2 \mathrm{C}$ global warming in European summer tourism. Climate Services, 1, 30-38.

Hotel Energy Solutions (2011), Analysis on Energy Use by European Hotels: Online Survey and Desk Research, Hotel Energy Solutions project publications

IPCC (2018) Global Warming of $1.5{ }^{\circ} \mathrm{C}$ Switzerland: Intergovernmental Panel on Climate Change

Instituto Nacional de Estadística (INE). INEbase. (2019) Available online: http://www.ine.es/inebmenu/indice.htm (accessed on February 1, 2019).

Katircioglu, S. T. (2014) International tourism, energy consumption, and environmental pollution: The case of Turkey. Renewable \& Sustainable Energy Reviews, 36, 180-187.

Katircioglu, S. T., Feridun, M. \& Kilinc, C. (2014) Estimating tourism-induced energy consumption and CO 2 emissions: the case of Cyprus. Renewable \& Sustainable Energy Reviews, 29, 634-640.

Krstinić Nižić, M., Šverko Grdić, Z. \& Hustić, A. (2016) The importance of energy for the tourism sector. Academica Turistica, 9(2), 77-83.

Labandeira, X., Labeaga, J. M., \& López-Otero, X. (2012). Estimation of elasticity price of electricity with incomplete information. Energy Economics, 34(3), 627-633.

Lee, C. \& Chiu, Y (2011). Electricity demand elasticities and temperature: Evidence from panel smooth transition regression with instrumental variable approach. Energy Economics, 33, 896-902.

Lin, B., \& Du, Z. (2015). How China' s urbanization impacts transport energy consumption in the face of income disparity. Renewable and Sustainable Energy Reviews, 52, 1693-1701.

Liu, Y., Gao, Y., Hao, Y., \& Liao, H. (2016). The Relationship between Residential Electricity Consumption and Income: A Piecewise Linear Model with Panel Data. Energies, 9(10), 831.

Massidda, C. \& Mattana, P. (2013), 'A SVECM. Analysis of the Relationship between International Tourism Arrivals, GDP and Trade in Italy', Journal of Travel Research, 52(1), 93-105.

Ministerio para la Transición Ecológica (2019). Estadísticas eléctricas anuales. 2018. Available online: https://energia.gob.es/balances/Publicaciones/ElectricasAnuales/Paginas/Electric asAnuales.aspx (accessed on February 1. 2019). 
Mohammadi, H., \& Ram, R. (2017). Convergence in energy consumption per capita across the US states, 1970-2013: An exploration through selected parametric and non-parametric methods. Energy Economics, 62, 404-410.

Pablo-Romero, M.P., \& Sánchez-Braza, A. (2017). Residential energy environmental Kuznets curve in the EU-28. Energy, 125, 44-54.

Pablo-Romero, M.P., Pozo-Barajas, R., \& Sánchez-Rivas, J. (2017a). Relationships between Tourism and Hospitality Sector Electricity Consumption in Spanish Provinces (1999-2013). Sustainability, 9(4), 480.

Pablo-Romero, M.P., Sánchez-Braza, A., \& Sánchez-Rivas, J. (2017b). Relationships between Hotel and Restaurant Electricity Consumption and Tourism in 11 European Union Countries. Sustainability, 9(11), 2109.

Pablo-Romero, M. P., Cruz, L., \& Barata, E. (2017c). Testing the transport energyenvironmental Kuznets curve hypothesis in the EU27 countries. Energy Economics, 62, 257-269.

Pesaran M. H. (2004). Pesaran, M. H. (2004). General Diagnostic Tests for Cross Section Dependence in Panels. https://doi.org/10.17863/CAM.5113

Pesaran M. H. A. (2007). Simple panel unit root test in the presence of cross section dependence, Journal of Applied Economics, 22(2), 265-312.

Pinto, A., Bernardino, M., Santos, A.S. \& Santo, F.E. (2016). Climate Change Impact Assessment in Hotels: Methodology And Adaptation Strategies For High Quality Hotels. WIT Transactions on The Built Environment, 161, 33-44.

Qureshi, M. I., Hassan, M. A., Hishan, S. S., Rasli, A. M., \& Zaman, K. (2017). Dynamic linkages between sustainable tourism, energy, health and wealth: Evidence from top 80 international tourist destination cities in 37 countries. Journal of cleaner production, 158, 143-155.

Serrano, S., Ürge-Vorsatz, D., Barreneche, C., Palacios, A., \& Cabeza, L. F. (2017). Heating and cooling energy trends and drivers in Europe. Energy, 119, 425-434.

Scott, D., Hall, C.M. \& Gössling, S. (2016a) A report on the Paris Climate Change Agreement and its implications for tourism: Why we will always have Paris. Journal of Sustainable Tourism, 24(7), 933-948.

Scott, D., Hall, C.M. \& Gössling, S. (2016b) A review of the IPCC 5th Assessment and implications for tourism sector climate resilience and decarbonization, Journal of Sustainable Tourism, 24(1), 8-30.

Turespaña (2019). Estadísticas de Demanda Turística. Available online: http://estadisticas.tourspain.es/es-es/turismobase/paginas/default.aspx (accessed on 1 February 2019).

Tsai, K.T., Lin, T.P., Hwang, R.L. \& Uang, Y.J. (2014) Carbon dioxide emissions generated by energy consumption of hotels and homestay facilities in Taiwan. Tourism Management, 42, 13-21.

United Nations. Paris Agreement. (2015). Available online: http://unfccc.int/files/ essential_background/convention/application/pdf/english_paris_agreement.pdf (Accessed on January 30, 2019).

UNWTO (2017). Tourism and the Sustainable Development Goals - Journey to 2030. Madrid: World Tourism Organization (UNWTO) and United Nations Development Programme (UNDP). 
Wang, J.C. (2012). A study on the energy performance of hotel buildings in Taiwan. Energy and Buildings, 49, 268-275.

Warnken, J., Bradley, M. \& Guilding, C. (2005) Eco-resorts vs. mainstream accommodation providers: an investigation of the viability of benchmarking environmental performance. Tourism Management, 26(3), 367-379.

Westerlund J. (2007). Testing for error correction in panel data. Oxford Bulletin of Economics and Statistics, 69(6), 709-48.

Wooldridge J. (2002). Econometric analysis of cross section and panel data; MIT Press: London, England. Available online: https://pdfs.semanticscholar.org/ 6bd0/adf734a194039061d085202808e5a0763289.pdf (Accessed on January 30, 2019).

Yin, H., Zhou, H. \& Zhu, K. (2015). Long-and short-run elasticities of residential electricity consumption in China: A partial adjustment model with panel data. Applied Economics, 48(28), 2587-2599.

Zaman, K., Shahbaz, M., Loganathan, N. \& Raza, S. A. (2016). Tourism development, energy consumption and Environmental Kuznets Curve: Trivariate analysis in the panel of developed and developing countries. Tourism Management. 54, 275-283. 
Table 1: Estimate results of [4]

\begin{tabular}{|c|c|c|c|c|}
\hline & $\begin{array}{c}\text { FGLS } \\
{[4]}\end{array}$ & $\begin{array}{c}\text { FGLS } \\
\text { [4] }\end{array}$ & $\begin{array}{c}\text { FGLS } \\
{[4]}\end{array}$ & $\begin{array}{c}\text { FGLS } \\
{[4]}\end{array}$ \\
\hline $\mathrm{T}$ & $\begin{array}{c}0.168^{* * * *} \\
(0.047)\end{array}$ & $\begin{array}{c}0.140^{* * * *} \\
(0.049)\end{array}$ & $\begin{array}{c}0.174 * * * \\
(0.049)\end{array}$ & $\begin{array}{c}0.130 * * * \\
(0.046)\end{array}$ \\
\hline $\mathrm{T}^{2}$ & $\begin{array}{c}0.077 * * * \\
(0.021)\end{array}$ & $\begin{array}{c}0.074^{* * * *} \\
(0.022)\end{array}$ & $\begin{array}{c}0.078 * * * \\
(0.022)\end{array}$ & $\begin{array}{c}0.076 * * * * \\
(0.020)\end{array}$ \\
\hline $\mathrm{Y}$ & $\begin{array}{c}0.756 * * * \\
(0.159)\end{array}$ & $\begin{array}{c}0.504^{* * * *} \\
(0.174)\end{array}$ & $\begin{array}{c}0.716^{* * *} \\
(0.169)\end{array}$ & $\begin{array}{c}0.548^{* * * *} \\
(0.166)\end{array}$ \\
\hline CDD18 & $\begin{array}{c}0.063 * * * \\
(0.022)\end{array}$ & & $\begin{array}{c}0.077 * * * \\
(0.021)\end{array}$ & \\
\hline HDD18 & $\begin{array}{c}0.080 * * \\
(0.037)\end{array}$ & & $\begin{array}{c}0.104 * * * \\
(0.033)\end{array}$ & \\
\hline CDD22 & & $\begin{array}{c}0.024 * * * \\
(0.009)\end{array}$ & & $\begin{array}{c}0.021 * * * \\
(0.009)\end{array}$ \\
\hline HDD15 & & $\begin{array}{c}0.017 \\
(0.020)\end{array}$ & & $\begin{array}{c}0.017 \\
(0.021)\end{array}$ \\
\hline ExtT & $\begin{array}{c}0.228^{* * *} \\
(0.108)\end{array}$ & $\begin{array}{c}0.214^{* * *} \\
(0.087)\end{array}$ & $\begin{array}{c}0.301 * * * \\
(0.110)\end{array}$ & $\begin{array}{c}0.213^{* *} \\
(0.110)\end{array}$ \\
\hline ST & $\begin{array}{l}0.138 * * \\
(0.062)\end{array}$ & $\begin{array}{c}0.265^{* *} \\
(0.121)\end{array}$ & $\begin{array}{l}0.130^{*} \\
(0.083)\end{array}$ & $\begin{array}{l}0.151^{* *} \\
(0.062)\end{array}$ \\
\hline $\mathrm{P}$ & $\begin{array}{c}0.002 \\
(0.040)\end{array}$ & $\begin{array}{l}-0.028 \\
(0.039)\end{array}$ & & \\
\hline
\end{tabular}

Table 2: Estimate results of [5]

\begin{tabular}{|c|c|c|c|c|}
\hline & $\begin{array}{c}\text { FGLS } \\
{[5]}\end{array}$ & $\begin{array}{c}\text { FGLS } \\
{[5]}\end{array}$ & $\begin{array}{c}\text { FGLS } \\
{[5]}\end{array}$ & $\begin{array}{c}\text { FGLS } \\
{[5]}\end{array}$ \\
\hline $\mathrm{T}$ & $\begin{array}{c}0.153 * * * \\
(0.049)\end{array}$ & $\begin{array}{c}0.140^{* * * *} \\
(0.045)\end{array}$ & $\begin{array}{c}0.100 * * * \\
(0.045)\end{array}$ & $\begin{array}{c}0.166^{* * * *} \\
(0.051)\end{array}$ \\
\hline $\mathrm{T}^{2}$ & $\begin{array}{c}0.071 * * * \\
(0.021)\end{array}$ & $\begin{array}{c}0.072^{* * * *} \\
(0.020)\end{array}$ & $\begin{array}{c}0.082 * * * \\
(0.018)\end{array}$ & $\begin{array}{c}0.071^{* * * *} \\
(0.021)\end{array}$ \\
\hline $\mathrm{Y}$ & $\begin{array}{c}0.731 * * * \\
(0.173)\end{array}$ & $\begin{array}{c}0.794^{* * * *} \\
(0.151)\end{array}$ & $\begin{array}{c}0.878^{* * * *} \\
(0.181)\end{array}$ & $\begin{array}{c}0.686^{* * * *} \\
(0.183)\end{array}$ \\
\hline CDD18 & $\begin{array}{c}0.095 * * * \\
(0.026)\end{array}$ & $\begin{array}{c}0.109^{* * * *} \\
(0.024)\end{array}$ & & \\
\hline HDD18 & $\begin{array}{c}0.103 * * \\
(0.042)\end{array}$ & $\begin{array}{c}0.160^{* * *} \\
(0.038)\end{array}$ & & \\
\hline CDD22 & & & $\begin{array}{c}0.045^{* * * *} \\
(0.011)\end{array}$ & $\begin{array}{c}0.032 * * * \\
(0.011)\end{array}$ \\
\hline HDD15 & & & $\begin{array}{c}0.047 * * \\
(0.022)\end{array}$ & $\begin{array}{c}0.024 \\
(0.024)\end{array}$ \\
\hline ExtT & $\begin{array}{l}0.219^{*} \\
(0.116)\end{array}$ & $\begin{array}{l}0.212^{*} \\
(0.119)\end{array}$ & $\begin{array}{c}0.408^{* * *} \\
(0.115)\end{array}$ & $\begin{array}{l}0.215^{*} \\
(0.126)\end{array}$ \\
\hline ST & $\begin{array}{c}0.113 * * * \\
(0.070)\end{array}$ & $\begin{array}{c}0.194 * * * \\
(0.054)\end{array}$ & $\begin{array}{c}0.244 * * * \\
(0.060)\end{array}$ & $\begin{array}{l}0.124^{*} \\
(0.071)\end{array}$ \\
\hline CDD*ExtT & $\begin{array}{c}0.007 \\
(0.116)\end{array}$ & $\begin{array}{c}0.029 \\
(0.112)\end{array}$ & $\begin{array}{l}-0.079 \\
(0.124)\end{array}$ & $\begin{array}{l}-0.011 \\
(0.126)\end{array}$ \\
\hline CDD*ST & $\begin{array}{l}0.209^{*} \\
(0.130)\end{array}$ & $\begin{array}{c}0.233^{* *} \\
(0.112)\end{array}$ & $\begin{array}{l}0.212^{*} \\
(0.136)\end{array}$ & $\begin{array}{l}0.240^{* *} \\
(0.136)\end{array}$ \\
\hline $\mathrm{P}$ & $\begin{array}{c}-0.004 \\
(0.0467)\end{array}$ & & $\begin{array}{l}-0.024 \\
(0.034)\end{array}$ & \\
\hline
\end{tabular}


Table 3: Estimate results of [6]

\begin{tabular}{|c|c|c|c|c|}
\hline & $\begin{array}{c}\text { FGLS } \\
{[6]}\end{array}$ & $\begin{array}{c}\text { FGLS } \\
{[6]}\end{array}$ & $\begin{array}{c}\text { FGLS } \\
{[6]}\end{array}$ & $\begin{array}{c}\text { FGLS } \\
{[6]}\end{array}$ \\
\hline $\mathrm{T}$ & $\begin{array}{c}0.133 * * \\
(0.053)\end{array}$ & $0.082 * * * \quad(0.029)$ & $\begin{array}{c}0.141 * * * \\
(0.063)\end{array}$ & $\begin{array}{c}0.135^{* * *} \\
(0.063)\end{array}$ \\
\hline $\mathrm{T}^{2}$ & $\begin{array}{c}0.070^{* * * *} \\
(0.024)\end{array}$ & $\begin{array}{c}0.062 * * * \\
(0.025)\end{array}$ & $\begin{array}{c}0.084 * * * \\
(0.025)\end{array}$ & $\begin{array}{c}0.083 * * * \\
(0.025) \\
\end{array}$ \\
\hline $\mathrm{Y}$ & $\begin{array}{c}0.779 * * * \\
(0.183)\end{array}$ & $\begin{array}{c}0.732 * * * \\
(0.201)\end{array}$ & $\begin{array}{l}0.518^{* *} \\
(0.219)\end{array}$ & $\begin{array}{c}0.555^{* * * *} \\
(0.217)\end{array}$ \\
\hline CDD18 & $\begin{array}{c}0.104 * * * * \\
(0.030)\end{array}$ & & & \\
\hline Squared-CDD18 & $\begin{array}{l}0.086 * * \\
(0.044)\end{array}$ & & & \\
\hline HDD18 & $\begin{array}{c}0.081 * * * * \\
(0.041)\end{array}$ & & & \\
\hline Squared-HDD18 & $\begin{array}{l}-0.050 \\
(0.046) \\
\end{array}$ & & & \\
\hline CDD22 & & $\begin{array}{c}0.068 * * * \\
(0.016)\end{array}$ & $\begin{array}{c}0.155 * * * \\
(0.051)\end{array}$ & $\begin{array}{c}0.158^{* * * *} \\
(0.051)\end{array}$ \\
\hline Squared-CDD22 & & $\begin{array}{c}0.044 * * * \\
(0.015)\end{array}$ & $\begin{array}{c}0.032^{* *} \\
(0.014)\end{array}$ & $\begin{array}{c}0.034^{* * * *} \\
(0.012)\end{array}$ \\
\hline HDD15 & & $\begin{array}{c}0.010 \\
(0.028)\end{array}$ & $\begin{array}{c}0.168 * * * \\
(0.060)\end{array}$ & $\begin{array}{l}0.134 * \\
(0.080)\end{array}$ \\
\hline Squared-HDD15 & & $\begin{array}{l}-0.004 \\
(0.015)\end{array}$ & $\begin{array}{c}-0.033 * * * \\
(0.016)\end{array}$ & $\begin{array}{c}-0.035 * * \\
(0.015)\end{array}$ \\
\hline CDD18-22 & & & $\begin{array}{c}0.133^{*} \\
(0.080)\end{array}$ & $\begin{array}{c}0.178^{* * * *} \\
(0.059)\end{array}$ \\
\hline HDD15-18 & & & $\begin{array}{c}0.367 * * * \\
(0.119)\end{array}$ & $\begin{array}{c}0.378^{* * * *} \\
(0.120)\end{array}$ \\
\hline ExtT & $\begin{array}{c}0.351 * * * * \\
(0.118)\end{array}$ & $\begin{array}{l}0.287^{*} \\
(0.140)\end{array}$ & $\begin{array}{c}0.282^{* *} \\
(0.144)\end{array}$ & $\begin{array}{l}0.308^{*} \\
(0.137)\end{array}$ \\
\hline ST & $\begin{array}{c}0.181 * * * * \\
(0.061)\end{array}$ & $\begin{array}{l}0.130^{*} \\
(0.074)\end{array}$ & $\begin{array}{l}0.124^{*} \\
(0.077)\end{array}$ & $\begin{array}{l}0.134^{*} \\
(0.076)\end{array}$ \\
\hline $\mathrm{P}$ & $\begin{array}{c}0.004 \\
(0.047)\end{array}$ & $\begin{array}{l}-0.062 \\
(0.050)\end{array}$ & $\begin{array}{l}-0.014 \\
(0.039)\end{array}$ & \\
\hline
\end{tabular}


Figure 1: Tourist overnight stays, hospitality electricity consumption and CDDHDD in the Spanish Mediterranean provinces.

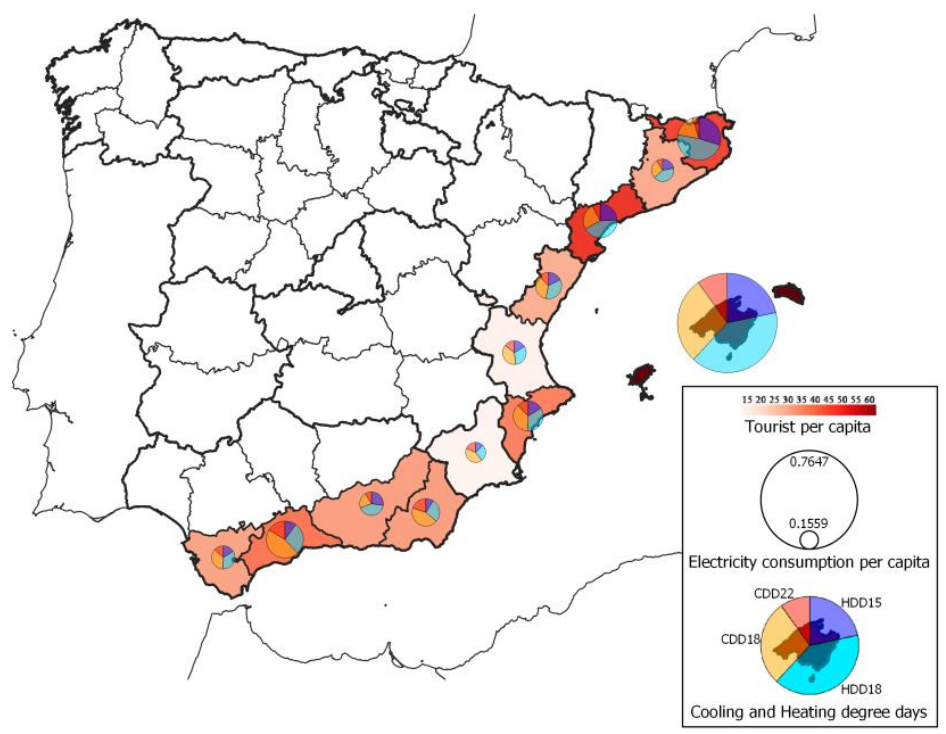

Source: own elaboration 